\title{
Donor-acceptor type low band gap polymers: polysquaraines and related systems $\dagger$
}

\author{
Ayyappanpillai Ajayaghosh* \\ Photosciences and Photonics Division, Regional Research Laboratory (CSIR), Trivandrum 695 \\ 019, India
}

Received (in Cambridge, UK) 7th January 2003, Accepted 26th March 2003

First published as an Advance Article on the web 2nd May 2003

\begin{abstract}
In recent years, considerable effort has been directed towards the synthesis of conjugated polymers with low optical band gaps $\left(E_{g}\right)$, since they show intrinsic electrical conductivity. One of the approaches towards the designing of such polymers is the use of strong donor and acceptor monomers at regular arrangements in the repeating units, which has limited success in many cases. An alternate strategy is the use of organic dyes, having inherently low HUMO-LUMO separation, as building blocks. Extension of conjugation in organic dyes is therefore expected to result in oligomers and polymers with near infrared absorption, which is a signature of low band gaps. Squaraine dyes are ideal candidates for this purpose due to their unique optical properties. This review highlights the recent developments in the area of donor-acceptor type low band gap polymers with special emphasis on polysquaraines.
\end{abstract}

A. Ajayaghosh was born in Kerala (God's own country), the south-west state of India in 1962. He obtained M. Sc. (1984) and Ph. D. (1988) in Chemistry from Calicut University. Subsequently he joined the Regional Research Laboratory, Trivandrum (CSIR, Government of India) as a scientist. He was an INSA-JSPS exchange fellow at Chiba University, Japan (1993), Alexander von Humboldt Fellow at MPI fuer Strahlenchemie, Germany (1994-96), CSIR-DAAD Visiting Fellow, University of Regensburg (1999) and DST-DAAD Visiting Fellow, University of Regensburg (2001 and 2002). He is a recipient of the Young Scientist Award by Indian Science Congress Association (1988), INSA Medal for Young Scientist by Indian National Science Academy (1993), Swarnajayanti Research Grant by

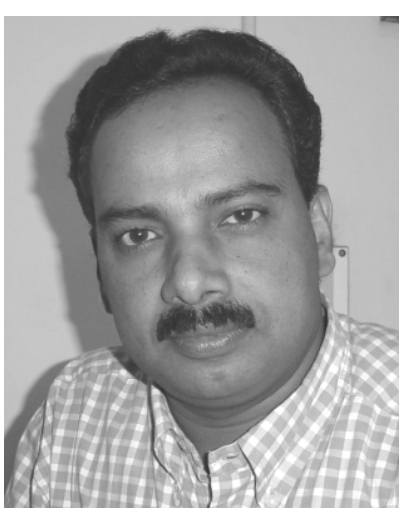

Department of Science and Technology (2001) and the CRSI Bronze Medal by Chemical Research Society of India (2002). He is a member of the Post Graduate Board of Studies in Chemistry of the Mahatma Gandhi University, Kottayam, Kerala. His research interests are in the areas of low band gap polymers, cation sensors, organogels, self-assembly of conjugated systems, light emitting polymers and photopolymerization.

$\dagger$ Electronic supplementary information (ESI) available: Table of band gap and conductivity values for a few bispyrrole derived polysquaraines. See http://www.rsc.org/suppdata/cs/b2/b204251g/

\section{Introduction}

The importance of $\pi$-conjugated polymers has been recognized with the recent spectacular developments in the area of optoelectronic and photonic material research. At the molecular level, $\pi$-conjugated systems represent the simplest models of molecular wires. The ability of conjugated systems to respond to external stimuli such as light, current and $\mathrm{pH}$ have contributed to the emergence of organic and polymeric materials for molecular electronics and logic functions. Since conjugated polymers form an integral part of several molecular electronic devices, considerable research effort, both in basic as well as in applied aspects, is being made with a view to developing new materials for information and communication technologies.

The first major breakthrough in the area of conjugated polymers was achieved in 1977 when MacDiarmid, Heeger and Shirakawa showed that polyacetylene, which is an insulator could become highly conducting on treatment with oxidizing or reducing agents. ${ }^{1,2}$ However, application of these polymers has been hampered to a large extent due to doping, which renders the polymer difficult to process except in a few recent cases. In this context, it is important to design conjugated polymers that show intrinsic conductivity (conductivity without doping) without compromising their solubility and processability. The band gap energy $\left(E_{g}\right)$, which is the energy gap between the highest occupied molecular orbital (HOMO) and the lowest unoccupied molecular orbital (LUMO) is the key factor, which determines the electronic and conducting properties of conjugated polymers. Therefore, control of the HOMO-LUMO gap by structural modification is extremely important in the designing of low $E_{g}$ polymers. Several molecular engineering strategies have been developed in recent years for the designing of low $E_{g}$ polymers via modification of their molecular structures. These aspects had been the subject of a recent review and hence will not be discussed in this article. ${ }^{3}$ The present review will concentrate on the donor-acceptor type polymers with special emphasis on squaraine dye based low band gap systems. Before considering the details of these aspects, it would be appropriate to have a brief mention on the band theory of conjugated polymers.

\section{Electrical conductivity and band gap of conjugated polymers}

The electronic and optical properties of $\pi$-conjugated polymers result from a limited number of states around the highest occupied and the lowest unoccupied levels. According to the band theory, the highest occupied band, which originates from the HOMO of each monomer unit, is referred to as the valance band and the corresponding lowest unoccupied band originating 
from the LUMO, as the conduction band. The evolution of bands in a conjugated polymer during its formation by

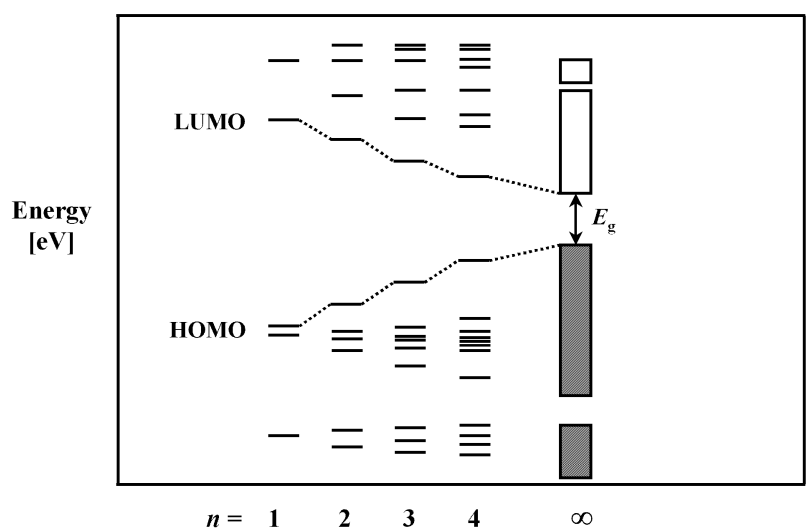

Fig. 1 Band formation during the polymerization of a conjugated monomer into a $\pi$-conjugated polymer.

monomer addition is shown in Fig. 1. The band gap $\left(E_{g}\right)$ of the polymer depends on the separation $\Delta E$ between the HOMO and LUMO energy levels of the monomers and the bandwidth $\mathrm{W}(\beta)$, which is a function of hybridization $(\beta)$ of monomer levels in the polymer.

The onset of the optical absorption spectrum of a conjugated polymer is a measure of the band gap of the polymer. Therefore, in order to achieve a low $E_{g}$, it is necessary to design polymers that absorb in the near infrared (long wavelength) region. However, in the case of conjugated polymers the optical absorption reaches the maximum value after a certain conjugation length, which is referred to as the effective conjugation length (ECL). ${ }^{4}$ Therefore, conventional approaches are not effective to synthesize conjugated polymers, which absorb in the NIR region. The ECL of conjugated polymers can be improved to a considerable extent by inducing the non-classical quinonoid character to the repeat units. An important development in this line is the report by Jenekhe, pertaining to the synthesis of poly(arylenemethines) 1a-c. 5 By varying the length and ratio of the quinonoid and aromatic blocks in 1a-c, the band gap could be tuned in between the limiting values for fully quinonoid and fully aromatic conjugated chains. Thus, polymers containing variable ' $x$ ' and ' $y$ ' blocks have been prepared, which showed band gaps as low as $0.75 \mathrm{eV}$. Later, Aota et al. reported polymers $\mathbf{2}$ and $\mathbf{3}$, the band gaps of which are reported to be less than $0.5 \mathrm{eV}$ (Fig. 2). ${ }^{6}$

Among the several recent approaches, the twist inhibition between consecutive repeating units of conjugated polymers using irreversible ladder type bonds, ${ }^{7,8}$ and zwitterionic structures involving alternating $\pi$-bonds ${ }^{9}$ are shown to be effective in the design of low $E_{\mathrm{g}}$ polymers. The band gap energy of conjugated polymers varies significantly depending upon the degree of extended conjugation between the consecutive repeating units and the inherent electron densities of the polymer backbones. In ladder type polymers, the extended $\pi$ conjugation can be maximized by H-bonding linkages between the repeating units, which consequently lower the optical band gaps or increase the bandwidth of the polymers. A copolymer 4 containing pyrrole and 2,1,3-benzothiadiazole moieties has been prepared by the polymerization of the corresponding monomers by a Pd-catalyzed reaction, which upon deprotection

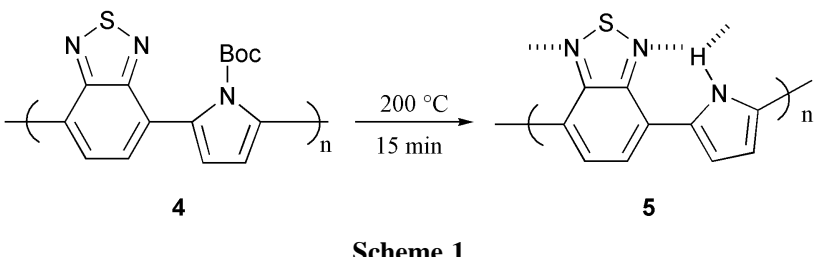

afforded the low $E_{g}$ polymer 5 (Scheme 1). ${ }^{10}$ This push-pull type polymer has a ladder-like structure based on intramolecular $\mathrm{H}$-bonding between the pyrrole $\mathrm{N}-\mathrm{H}$ and the 2,1,3-benzothiadiazole imine nitrogen. Zwitterionic polymers, which are capable of undergoing structural reorganization are known to possess low band gaps. For example, Brockmann and Tour have reported the synthesis of novel zwitterionic pyrrole-derived monomers, which afforded unique polymers $(\mathbf{7 a}, \mathbf{b})$ by a $\mathrm{Cu}$ catalyzed polymerization reaction (Scheme 2 ). These polymers

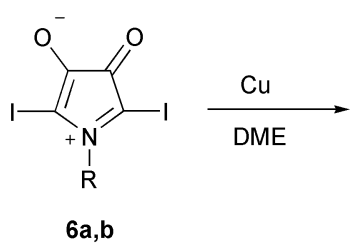

a, $\mathrm{R}=\mathrm{C}_{4} \mathrm{H}_{9}$ b, $\mathrm{R}=\mathrm{C}_{12} \mathrm{H}_{25}$

Scheme 2

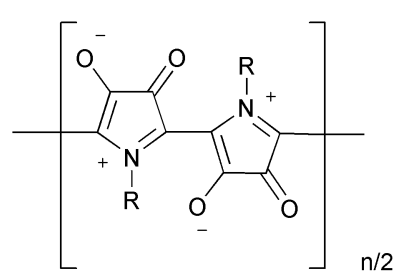

7a,b

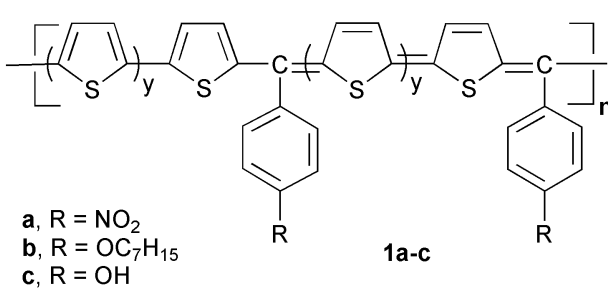<smiles></smiles>

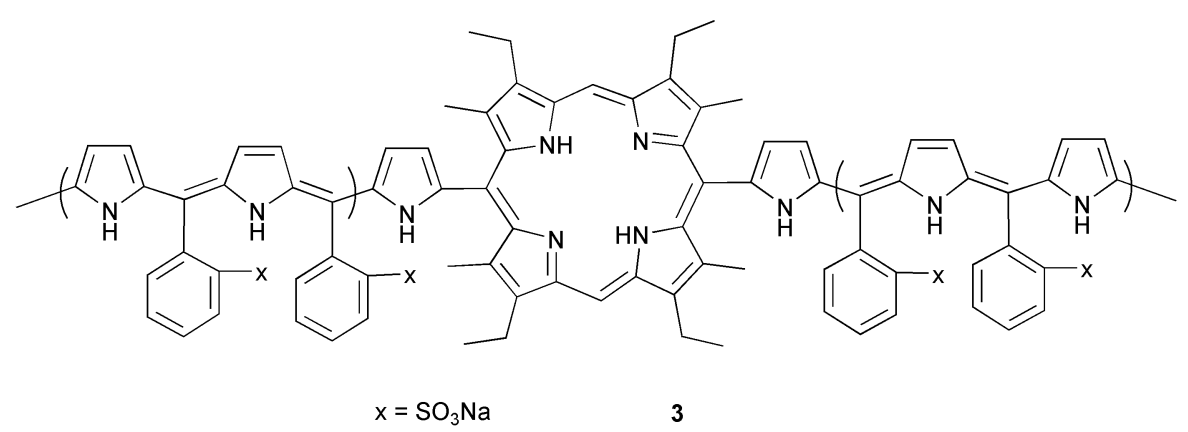

Fig. 2 
undergo reversible optical shift from the visible to the near IR region with a solution band gap of approximately $1.1 \mathrm{eV}$ (Fig. 3). ${ }^{9}$ These polymers showed solvent and metal cation induced reversible planarization of the polymer backbone which is responsible for the low solution band gap.

\section{Donor-acceptor systems}

A strategy to induce minimum twisted arrangements between consecutive repeating units in conjugated polymers involves construction of A-B type systems where the ' $\mathrm{A}$ ' unit has strong electron-donating and the ' $\mathrm{B}$ ' unit has strong electron-withdrawing moieties. Interaction of the donor-acceptor moieties enhances the double bond character between the repeating units, which stabilizes the low band gap quinonoid-like forms within the polymer backbones. Hence, a conjugated polymer with an alternating sequence of the appropriate donor and acceptor units in the main chain can induce a reduction in its band gap energy.

Recent molecular orbital calculations have shown that the hybridization of the energy levels of the donor and the acceptor moieties result in D-A systems with unusually low HOMOLUMO separation. ${ }^{11}$ If the HOMO levels of the donor and the LUMO levels of the acceptor moiety are close in energy the resulting band structure will show a low energy gap as depicted in Fig. 4. Further hybridization upon chain extension reduces the band gap as shown in Fig. 1. During the progress of polymerization, the HOMO and LUMO levels of the repeating unit disperse into the valance and conduction bands. At each stage of monomer addition, the magnitudes of the LUMO $\left(W_{L}\right)$ and the HOMO bands $\left(W_{H}\right)$ increase, which strongly depend upon the degree of overlap between the aromatic orbitals in the coupling position of the monomer units. Thus, $W_{L}$ and $W_{H}$ get maximum values at an unobstructed overlap and in such a condition the molecule can exist in its lowest band gap level. However, deviations from this ideal situation may occur when the steric hindrance forces the consecutive aryl units out of plane or when the size of the atomic orbitals (AOs) at the coupling position is diminished.

Further reduction in band gap is possible by enhancing the strength of donor and acceptor moieties via strong orbital interactions. In donor-acceptor systems, the introduction of electron withdrawing groups reduces $E_{g}$ by lowering the LUMO levels whereas, the introduction of electron donating groups reduces $E_{g}$ by raising the HOMO levels. Therefore, designing of extremely low $E_{g}$ polymers requires strong donors and

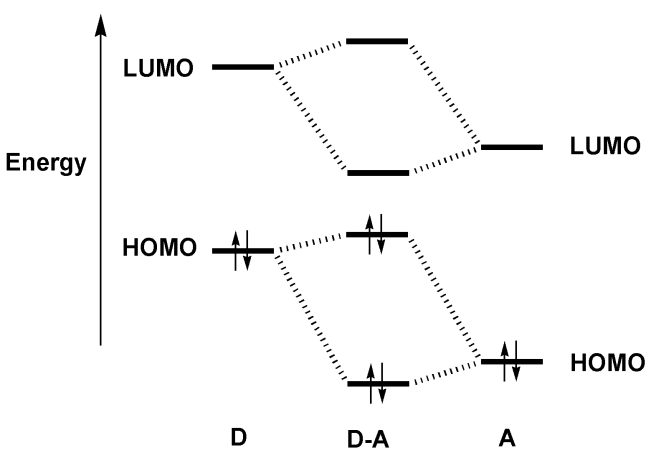

Fig. 4 Molecular orbital interaction in donor (D) and acceptor (A) moieties leading to a D-A monomer with an unusually low HOMO-LUMO energy separation (adapted from ref. 12)

acceptors. Commonly employed electron-donating moieties are thiophene and pyrrole with various substitution patterns, which often represent the best choice since these are electron rich subunits that allow numerous chemical transformations. The most widely used electron withdrawing groups are cyano and nitro groups. In addition copolymers containing electron withdrawing moieties such as quinoxalines, pyrazines and thiadiazoles, are reported to possess low band gaps. Using combinations of these donor and acceptor groups, a variety of monomers have been synthesized which undergo facile electrochemical or chemical polymerization leading to the formation of a number of low band gap polymers, a few representative examples of which are shown in Figs. 5 and $6 .{ }^{12-15}$

Conjugated polymers (12-15) containing pyrrole and/or thiophene as electron donating and cyano-substituted aryl unit as electron accepting groups have been prepared by electrochemical oxidation methods (Fig. 6). ${ }^{14,15}$ The band gaps<smiles></smiles>

$10 a-c$<smiles>[R]c1c(C)sc(/C(C#N)=C/c2sc(C(C)(C)C)c3c2OCCO3)c1[R]</smiles>

$\mathrm{a}, \mathrm{R}=\mathrm{H}$

$b, R=0$
Fig. 5
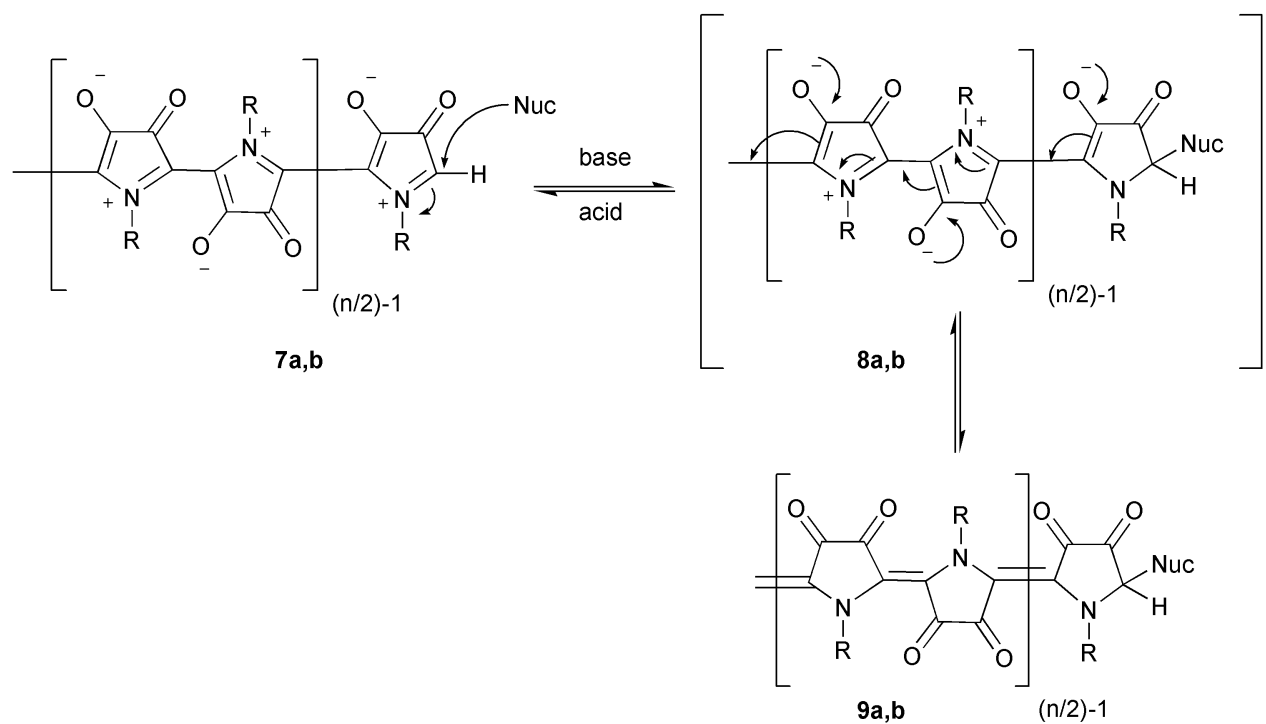

Fig. 3 Reversible planarization of a pyrrole derived zwitterionic polymer. 
<smiles>CC(C)(C)c1ccc(/C=C(\C#N)c2ccc(C(C)(C)C)[nH]2)[nH]1</smiles>

12<smiles></smiles>

13<smiles>Cc1ccc(-c2ccc(-c3ccc(C(C)(C)C)[nH]3)c(C#N)c2)[nH]1</smiles><smiles>Cc1ccc(/C=C(\C#N)c2ccc(/C(C#N)=C/c3ccc(C(F)(F)F)[nH]3)s2)[nH]1</smiles>

15

Fig. 6

estimated for these polymers are much lower when compared to similar polymers without a cyano-group. Exceptionally, polymer 14 exhibits a much higher $E_{\mathrm{g}}$ value because of the enhanced steric hindrance along the pyrrole-phenyl bond. A polythiophene 17 containing nitro groups as the electron acceptors and amino groups as electron donors is reported by Zhang and Tour (Scheme 3). ${ }^{16}$ Solution and solid-state optical band gaps of<smiles>CC(C)(C)OC(=O)Nc1c(C(=O)OC(C)(C)C)sc(-c2sc(C(C)(C)C)c(NC(=O)OC(C)(C)C)c2[N+](=O)[O-])c1[N+](=O)[O-]</smiles>

16

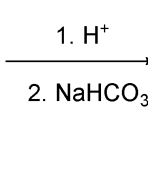

Scheme 3 the polymer $\mathbf{1 7}$ are 1.4 and $1.1 \mathrm{eV}$, respectively. This low $E_{\mathrm{g}}$ observed in the solid state, suggests that the conjugated backbone is rigid due to the contribution of the mesomeric structure 18, which may presumably be weak in the solution state (Scheme 4).<smiles>Cc1sc(-c2sc(C(C)(C)C)c([N+](=O)[O-])c2[N+](=O)[O-])c(N)c1N</smiles><smiles>CCCC</smiles>

17

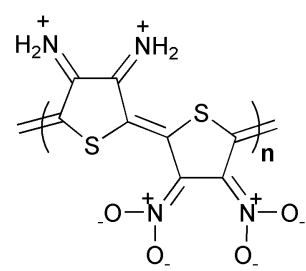

18
Scheme 4

Yamashita and coworkers have reported a variety of low band gap polymers containing pyrazine or thiadiazole acceptor units, which are fused onto phenyl (Fig. 7) or thiophene (Fig. 8) rings. ${ }^{17}$ The polymers in which the electron acceptor moieties are attached to a thiophene are known to have better reduction in band gaps. Since the coupling positions are part of a 5-membered thiophene ring, the electron donating sulfur atom will contribute more to the orbital coefficients. A number of<smiles>[R]c1nc2c(-c3ccc(C(C)(C)C)s3)ccc(-c3ccc(C(C)(C)C)s3)c2nc1[R]</smiles>

19<smiles>[R]c1nc2c(-c3ccc(C(C)(C)C)s3)ccc(C(C)(C)C)c2nc1[R]</smiles>

20

Fig. 7<smiles>CC(C)(C)c1ccc(-c2sc(-c3ccc(C(C)(C)C)s3)c3nccnc23)s1</smiles>

22<smiles>[Z4]c1sc(-c2ccc(C(C)(C)C)[nH]2)c2c1N=S=N2</smiles><smiles>CC(C)(C)c1ccc(-c2sc(-c3ccc(C(C)(C)C)s3)c3c2N=S=N3)s1</smiles>

23<smiles>[Z6]c1ccc(-c2sc(-c3ccc(C(C)(C)C)[nH]3)c3nccnc23)[nH]1</smiles>

25

Fig. 8

trimeric thiophene derivatives have been synthesized in which the middle thiophene unit is fused with pyrazine or thiadiazole moieties which can subsequently be electropolymerized to the corresponding low band gap polymers 22 and 23 , respectively. The optical absorption and redox properties of $\mathbf{2 2}$ can be appreciably controlled by placing appropriate substituents on the pyrazine and thiophene rings. Compared to isothianaphthalene derivatives, the thienothiadiazole moiety of the polymer $\mathbf{2 3}$ has a lower HOMO-LUMO gap. Excellent results were obtained by the electropolymerization of pyrrole-based monomers containing thienothiadiazole or pyrazine as the acceptor and pyrrole as the donor leading to polymers $\mathbf{2 4}$ and $\mathbf{2 5}$, respectively. Electropolymerization of a bithiophene monomer containing alternate pyrazine and dioxoethylene moieties resulted in a donor-acceptor polymer 27 with a reported band gap of $0.36 \mathrm{eV}$ (Scheme 5). ${ }^{18}$

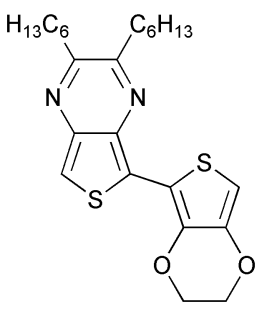

26

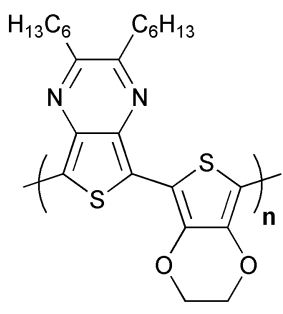

27

Scheme 5

Electron withdrawing power of quinoxaline or 2,1,3-benzothiadiazole can be further increased by fusion of another pyrazine or thiadiazole ring onto the vacant sites of the phenyl ring to yield pyrazinoquinoxaline, thiadiazoloquinoxaline and benzobis(thiadiazole). ${ }^{19}$ The corresponding polymers 28a-c (Fig. 9), were prepared electrochemically from their thiophene 
<smiles>Cc1ccc(-c2c3c(c(-c4ccc(C)s4)c4nsnc24)N=S=N3)s1</smiles>

$28 a$

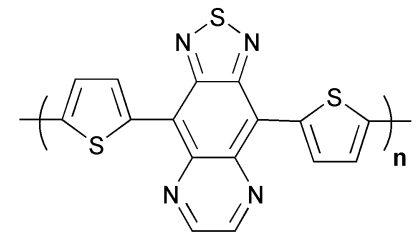

28b<smiles>Cc1nc2c(-c3ccc(C(C)(C)C)s3)c3nc(C)c(C)nc3c(-c3ccc(C(C)(C)C)s3)c2nc1C</smiles>

Fig. 9

linked monomers. The reported band gaps of these polymers are $0.5,0.7$ and $0.9 \mathrm{eV}$, respectively. In a subsequent paper, Tanaka and Yamashita have reported the synthesis of a series of mixed trimers composed of aromatic heterocycles and a thiophene with pyrazine-dihydropyrazine redox system (Scheme 6). ${ }^{20}$<smiles>[X]c1sc([X])c2c1Nc1nsnc1N2</smiles>

29a-e

reduced form

high $E_{g}$ classical system

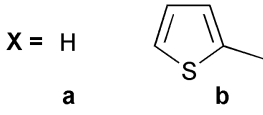

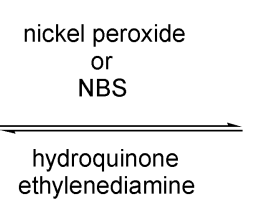

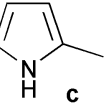

Scheme 6

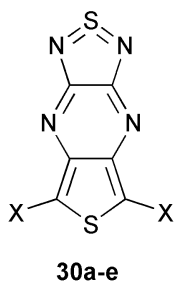

oxidized form low $E_{g}$ non classical system

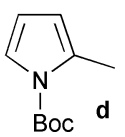<smiles>c1csc(Cc2nccs2)n1</smiles>

The oxidized forms of these compounds have much lower optical and electrochemical energy gaps when compared to many of the above reported systems. The pyrrole derivative 30c showed a $1000 \mathrm{~nm}$ red shift of the absorption band when compared to the corresponding terthiophene $\mathbf{3 0 b}$. The reported band gap of 30c is around $0.6 \mathrm{eV}$.

The various examples cited above reveal that the trimeric precursor, containing electron accepting and donating groups, offer several possibilities to the designing of conjugated polymers whose electronic properties and band gaps can be tuned by varying the electron donor-acceptor strength of the monomers. This approach has been successfully used for the electrochemical synthesis of several copolymers, containing hybrid ring systems, leading to polymers with the lowest band gaps reported so far. However, the high lying HOMO levels of some of the precursors limit the efficiency of their electropolymerization. In addition, large-scale synthesis of low band gap polymers by electrochemical approach is not feasible. In this context, development of simple chemical procedures to the synthesis of low band gap polymers has become extremely important.

In order to understand the effect of structural variations that lead to the narrowing of band gap in donor-acceptor conjugated systems, van Mullekom et al. have synthesized a variety of cooligomers 31-33 consisting of pyrrole or thiophene as the electron releasing unit and quinoxaline or 2,1,3-benzothiadia- zole as the electron withdrawing moieties using Pd-catalysed Stille coupling strategy (Fig. 10). ${ }^{21}$ When the absorption

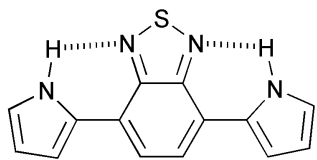

31

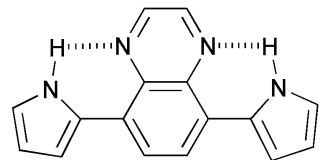

32

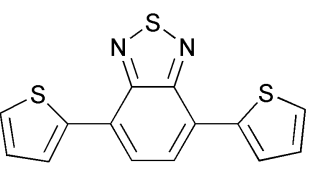

33

Fig. 10

maximum energies of these oligomers were plotted as a function of the reciprocal number of the aryl units $(1 / n)$, considerable deviation could be seen when compared to homooligomers such as oligothiophenes and oligopyrroles. From these plots it has been predicted that, in order to get a polymer with an absorption maximum below $1 \mathrm{eV}$, the corresponding $\mathrm{D}$ A codimer must show an absorption maximum $>500 \mathrm{~nm}$, whereas a hypothetical polymer with a band gap of $0 \mathrm{eV}$ requires a codimer with an absorption maximum of at least 990 $\mathrm{nm}$. In this context it has been proposed that the donor-acceptor cotrimer 34 reported by Tanaka and Yemashita, which shows an<smiles>c1c[nH]c(-c2sc(-c3ccc[nH]3)c3nc4c(nc23)N=S=N4)c1</smiles>

34

absorption maximum of $1345 \mathrm{~nm}$ would be an ideal candidate for the synthesis of extremely low $E_{g}$ polymer with intrinsic metallic conductivity. ${ }^{20}$ However, due to the poor stability, synthesis of $\mathbf{3 4}$ is difficult. An alternate compound for consideration is the cotrimer $\mathbf{3 5}$, which is stable under ambient<smiles>c1csc(-c2c3c(c(-c4cccs4)c4nsnc24)N=S=N3)c1</smiles>

conditions with a narrow HOMO-LUMO separation. This compound has an absorption maximum of $700 \mathrm{~nm}$ and the corresponding polymer has a band gap of $0.5 \mathrm{eV}$.

In search of small band gap polymers, so far the main focus has been on the increase of bandwidth $\mathrm{W}(\beta)$, by going from aromatic to quinonoid structures. The donor-acceptor strategy has been widely used for this purpose as evident from the many examples cited above. However, the most frequently used monomers, such as thiophene, pyrrole, phenylene or vinylene, have too large HOMO-LUMO gap $(\Delta E)$, which can only be partially closed by band formation. Hence in order to achieve a polymer with a smaller band gap, it would be necessary to start from monomers with a small $\Delta E$, such as in organic dye molecules. ${ }^{11}$ 


\section{Squaraine dyes as building blocks for low band gap polymers}

Donor-acceptor type organic dye molecules in general have intense absorption in the visible to the near infrared region, which means that they have an inherently low HOMO-LUMO energy gap. Extension of the conjugation length and strengthening of the donor-acceptor interaction in such dyes can generate polymers with low band gap energy and intrinsic conductivity. Squaraine dyes are the best among the different class of dyes for this purpose. They are condensation products of electron rich aromatic and heterocyclic molecules such as $N, N$-dialkylanilines, benzothiazoles, phenols, azulenes and pyrroles with 3,4-dihydroxy-3-cyclobutene-1,2-dione (squaric acid). ${ }^{22}$ They are highly colored zwitterionic dyes, which possess intense absorption in the visible to the near-infrared region. A representative example is shown in Scheme 7.

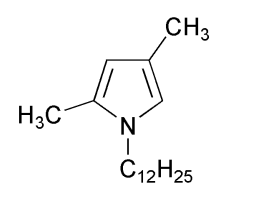

36

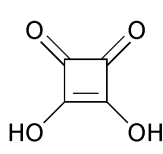

37

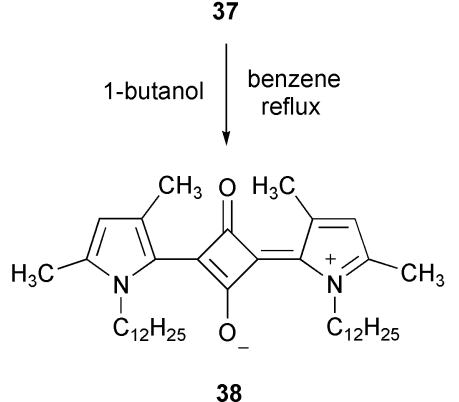

Scheme 7
In the solid state, due to strong intermolecular donoracceptor interactions, the absorption of these dyes becomes very broad and red-shifted to near IR region. These properties have made squaraines ideally suited for applications in xerographic photoreceptors, solar cells and optical recording media. ${ }^{23}$ Electron rich aromatic compounds with two reactive end functional groups can react with electron deficient squaric acid, resulting in the formation of polymeric dyes with extended conjugation, which absorb in the visible to the NIR region.

The first report on a squaraine based polymer can be traced back to 1965, when Triebs and Jacobs reported the formation of an insoluble material $\mathbf{4 0}$ upon reaction of pyrrole with squaric acid (Scheme 8$).{ }^{24}$ The intractable nature of this material has<smiles>c1cc[nH]c1</smiles>

39<smiles>CC1(C)C(=O)C(=O)C(O)=C1O</smiles>

37

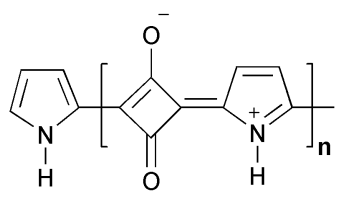

40
Scheme 8

prevented further studies of its properties. Later, Chen and Hall reported the polycondensation of squaric acid with $\mathrm{N}$-alkylcarbazoles, which resulted in the formation of an insoluble polymer 41 having $36-43 \%$ of 1,2-oriented squarate units based on IR spectral analysis. ${ }^{25}$ However, polycondensation of squaryl dichloride with $\mathrm{N}$-1-butylcarbazole in nitrobenzene gave polymers having $100 \%$ of 1,2-oriented squarate units which are soluble in organic solvents. In these cases the electrical conductivities were as low as $10^{-9} \mathrm{~S} \mathrm{~cm}^{-1}$, which did not show any change upon doping with iodine.<smiles></smiles>

41

Havinga et al. have made significant contributions to the synthesis and studies of several polysquaraines and polycroconaines. ${ }^{26,27}$ Condensation of benzobisthiazoles with squaric acid and croconic acid (a higher homologue of squaric acid), resulted in several polysquaraines (43) and polycroconaines (45), respectively, some of which showed absorption close to the near infrared region (Schemes 9 and 10). The band gaps of<smiles>[R]N1C(=C)Sc2cc3c(cc21)SC(=C)N3[R]</smiles>

42<smiles>O=c1c(O)c(O)c1=O</smiles>

37<smiles>[R]N1C(=C)Sc2cc3c(cc21)sc(C=C1C(=O)C(CC(C)(C)C)=C1O)[n+]3[R]</smiles>

Scheme 9<smiles>[R]N1C(=C)Sc2cc3c(cc21)SC(=C)N3[R]</smiles>

42<smiles>O=c1c(O)c(O)c(=O)c1=O</smiles>

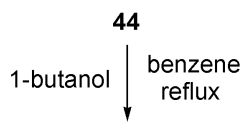<smiles>[R]N1/C(=C/C2=C([O-])C(=CC(C)(C)C)C(=O)C2=O)Sc2cc3c(cc21)sc(C(C)(C)C)[n+]3[R]</smiles>

Scheme 10 these polymers were in the range of $1.0-0.5 \mathrm{eV}$. Due to the better donor-acceptor interactions, polycroconaines showed lower band gaps when compared to the polysquaraines. Even though the band gaps of the different squaraine polymers are nearly the same, their conductivities showed large variation between $10^{-4}-10^{-7} \mathrm{~S} \mathrm{~cm}^{-1}$. More recently, Havinga et al. have reported the synthesis of the water soluble polysquaraines $\mathbf{4 6}$ and 47 and the polycroconaine 48 in order to evaluate their optical and photoconductivity band gaps (Fig. 11). ${ }^{28} \mathrm{~A}$ comparison of the solid-state absorption spectra of these polymers with photoconductivity profiles revealed that the absorption gives rise to charge carriers and hence the absorption edge coincides with the band gap between the conduction and valence bands. The conductivity of these polymers could be increased to $1 \mathrm{~S} \mathrm{~cm}^{-1}$ by doping with oxidants such as iodine 


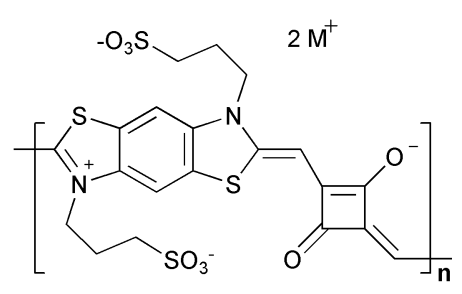

46

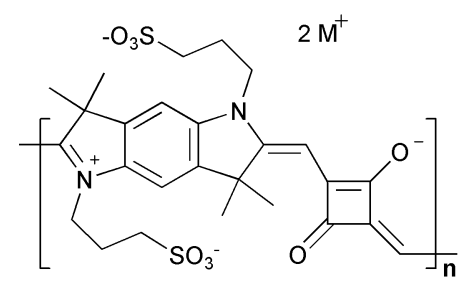

47

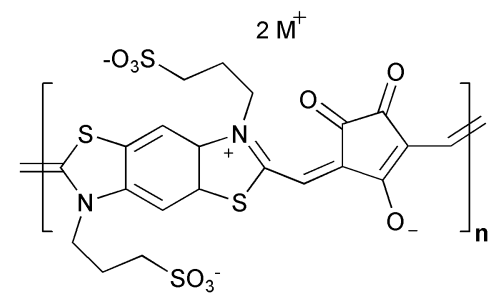

48

Fig. 11

and DDQ. According to Havinga et al. the low band gaps in polysquaraines can be due to the fact that their conjugated main chain with alternation of electron withdrawing and donating moieties represents the one-dimensional analogue of an $n-i-p-i$ semiconductor structure in which the valence and the conduction bands are curved by space charge effects. ${ }^{27}$

\section{Pyrrole derived polysquaraines}

Squaric acid is known to condense with $N$-alkyl substituted pyrroles where both 2 and 5 positions are free to react thereby forming partially soluble dark blue polymers. ${ }^{24}$ Lynch and coworkers have reported the synthesis of several pyrrole based polysquaraines in order to study their non-linear optical properties. ${ }^{29-31}$ In parallel, Ajayaghosh and coworkers have reported the synthesis and properties of a series of oligo- and polysquaraines 49-52 derived from pyrrole derivatives that are soluble in organic solvents (Fig. 12). ${ }^{32-34}$ Polymers 49 and 50 showed interesting properties such as $\mathrm{pH}$ and solvent dependent changes in the optical properties. It has been reported that the properties of these polymers can be manipulated by incorporating the 1,2-diketonic repeating units, resulting in the formation of polymers $\mathbf{5 1}$ and $\mathbf{5 2}$, which depends upon the reaction conditions. The oligosquaraine 53a was water soluble and showed higher conductivity when compared to 49 and 50 . A variety of water soluble random oligomers $\mathbf{5 3 b}-\mathbf{e}$ having mixed

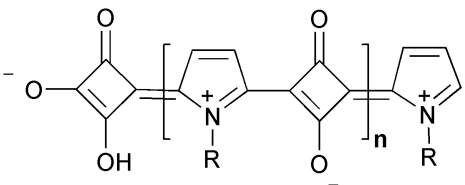

a, $\mathrm{R}=\mathrm{C}_{12} \mathrm{H}_{25}$ b, $\mathrm{R}=\mathrm{C}_{11} \mathrm{H}_{22} \mathrm{OH}$

$49 a, b$

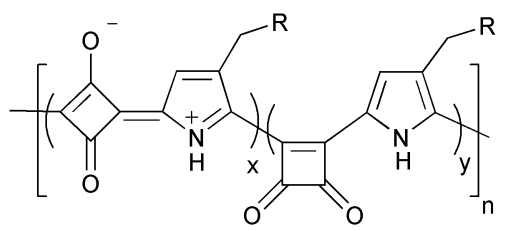

51

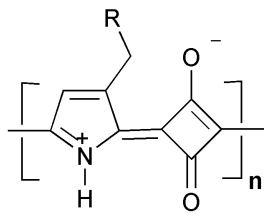

$\mathrm{R}=\mathrm{C}_{11} \mathrm{H}_{23} \quad \mathbf{5 0}$

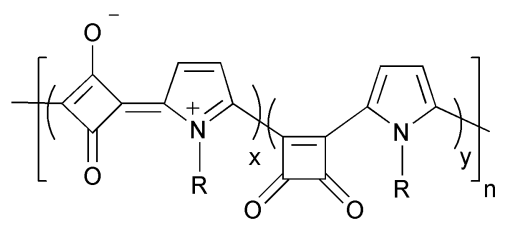

52

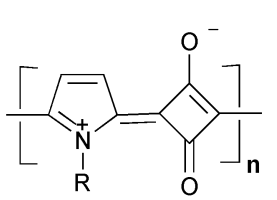

$53 a$

$\mathrm{R}=\mathrm{C}_{3} \mathrm{H}_{6} \mathrm{SO}_{3}{ }^{-} \mathrm{Na}^{+}$
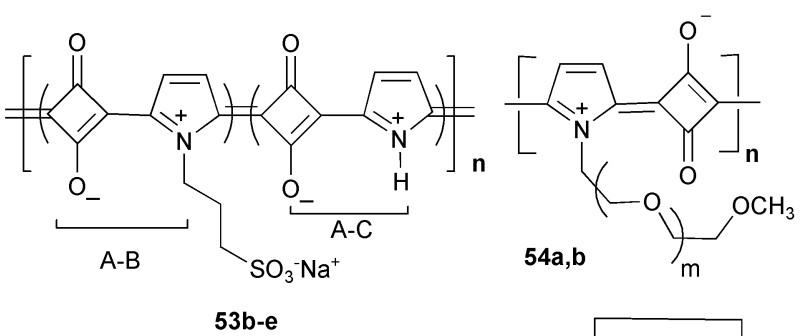

a, $m=1$

b, $m=2$

Fig. 12 
squaraine dye units were prepared by the polycondensation of sodium 3-(propyl-1-yl)propanesulfonate and pyrrole with squaric acid. ${ }^{33}$ The conductivities of these random oligomers are shown to depend upon the composition of the A-B and A-C repeating units. The polysquaraine 54 containing the oxyethylene side chain showed enhanced specificity and selectivity towards the detection of $\mathrm{Li}^{+}$over $\mathrm{Na}^{+}$and $\mathrm{K}^{+} .35,36$ The cation sensing property of polysquaraines having different oxyethylene chains was studied using the change in fluorescence emission before and after the binding of different metal cations. The enhancement of fluorescence after metal binding suggests a planar rigid structure to the polymer backbone as shown in Scheme 11. Similar studies were performed with model squaraine dyes, however the binding response was very weak in such cases. This observation suggests the importance of a macromolecular structure in the signal amplification during a metal binding.

Lynch et al. have synthesized a series of polysquaraines from oligo(1-methylpyrroles) to investigate their electrical conduction properties. ${ }^{37}$ In this series, only the tetramer-derived polysquaraine (Sq.Py4) showed electric conduction $\left(2 \times 10^{-7}\right.$ $\mathrm{S} \mathrm{cm}^{-1}$ ), whereas the dimer and trimer derived polysquaraines are insulators with a dielectric breakdown of $1-0.05 \mathrm{MV} \mathrm{cm}^{-1}$. It is not clear whether the low conductivity of Sq.Py4 is due to any unintentional doping. The X-ray powder diffraction analysis of Sq.Py4 indicates that this polymer has a onedimensional order with a close interlayer spacing of $3.4 \AA$, which corresponds to $3.6-3.8 \AA$ in several of the other related systems. These results indicate that a consideration of the solidstate packing is important in predicting the electrical conducting properties of these materials.

It is surprising to note that, except in a few cases, none of the above polymers showed the expected low band gaps. This is in contrast to the theoretical prediction that extension of conjugation in squaraine dyes can lead the formation of low band gap polymers. ${ }^{11}$ This could be due to the fact that in polysquaraines the low band gaps are originating from a narrow HOMOLUMO energy separation, typical of donor-acceptor (D-A) fragments. However, on chain extension through polymerization of each D-A fragment, the hybridization not only raises the energy of HOMO but also the LUMO level by a similar amount. Therefore, in polysquaraines, both HOMO and LUMO levels are shifted up equally and hence no considerable reduction in band gap is observed. Under this condition, the construction of extremely low band gap polysquaraine is possible only by allowing the HOMO level to participate in hybridization and the LUMO level is 'frozen' at the originally low value of the fragment. The exclusion of the LUMO level from hybridization does not alter its energy levels during chain extension whereas, the HOMO energy increases during hybridization, which eventually leads to a narrow band gap. This 'freezing' of the LUMO level may be annihilating the overlap of these orbitals throughout the polymer chain, by making this interaction symmetry forbidden. This may be the case of the hypothetical polymers $\mathbf{5 5}$ and $\mathbf{5 6}$ as illustrated in Fig. 13.

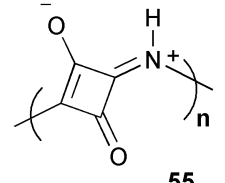

55

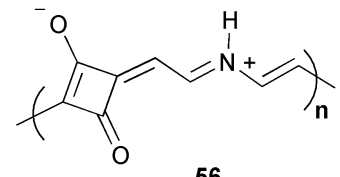

56

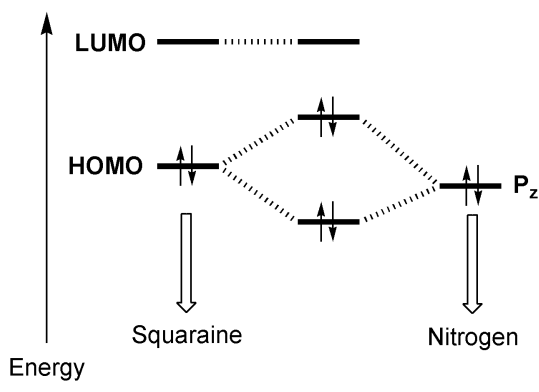

Fig. 13 "Freezing" of the LUMO level at its originally low value by introducing nitrogen atoms in the main chain of polysquaraine copolymers (adapted from ref. 12).

The interaction between the HOMO of squaraine and the $p_{z}$ orbital of nitrogen results in a hybridization upon chain extension. Since the interaction between the nitrogen $\mathrm{p}_{z}$ orbital and the LUMO of squaraine is forbidden for symmetry reasons, the LUMO energy level is unaffected. However, the symmetry allowed interactions of HOMO with $\mathrm{p}_{\mathrm{z}}$ orbital, shift the energy of HOMO and consequently the band gap energy decreases. The calculated band gap of the polymer $\mathbf{5 6}$ is as low as $0.2 \mathrm{eV}$. The decrease in band gap energy of $\mathbf{5 6}$ over $\mathbf{5 5}$ is probably due to the effect of increased conjugation in $\mathbf{5 6}$. Hence by the extension of conjugation by choosing symmetrically allowed interaction between the HOMO level of squaraine and $\mathrm{p}_{\mathrm{z}}$ orbital of nitrogen containing heterocycles, one can ideally design extremely low $E_{\mathrm{g}}$ polysquaraines.

Contrary to the above reasoning, the early attempts to synthesize low $E_{g}$ polysquaraines using $N$-alkyl substituted pyrroles were not successful. This shows that a mere extension of conjugation in these systems is not sufficient to decrease the band gaps. For example, the squaraine dye $\mathbf{5 7}$ has an absorption maximum of $547 \mathrm{~nm}$ whereas the corresponding polysquaraine has an absorption maximum of $580 \mathrm{~nm}$, a mere increase of 33 $\mathrm{nm}$. On the other hand, the $\pi$-extended squaraine dye $\mathbf{5 9}$ showed a red shift of $148 \mathrm{~nm}\left(\lambda_{\max }=695 \mathrm{~nm}\right)$ when compared to the absorption maximum of 57 (Fig. 14). At this point it is interesting to note why the polymer $\mathbf{5 8}$ was not showing the expected long wavelength absorption (low $E_{g}$ ) despite its extended conjugation. This can be explained by considering the polymer $\mathbf{5 8}$ as a repeating structure of a squaraine dye as shown by the structure 60. The overall structure of the polymer can thus be considered as a copolymer of a donor-acceptor-donor (D-A-D) type squaraine repeating unit, which is bridged through an electron deficient cyclobutene unit (A) as shown in Fig. 15. In such a case, the donor-acceptor-donor interaction of

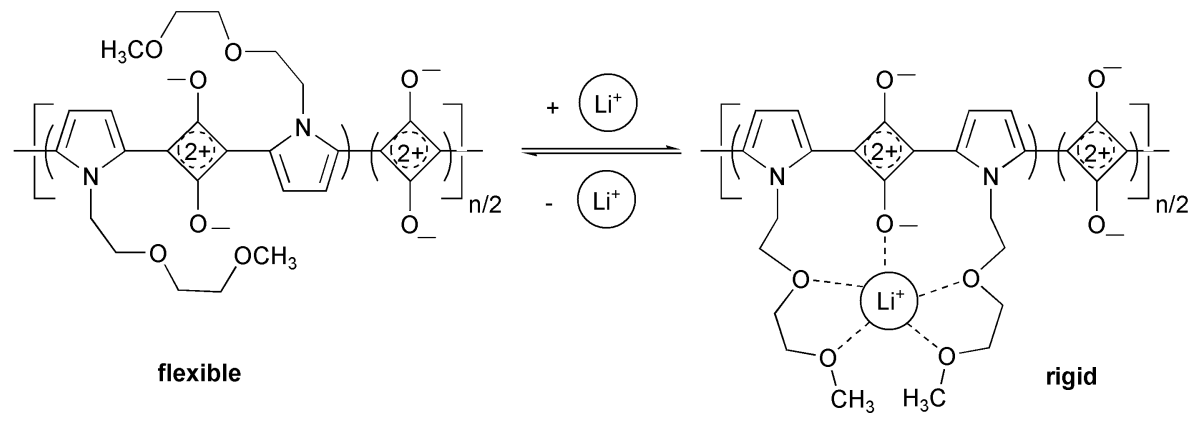

Scheme 11 


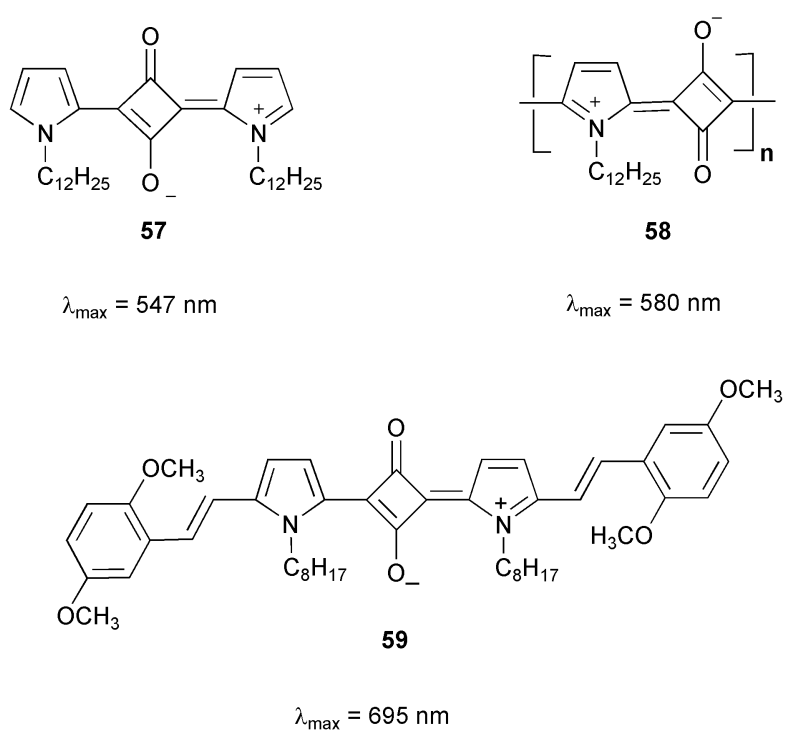

Fig. 14

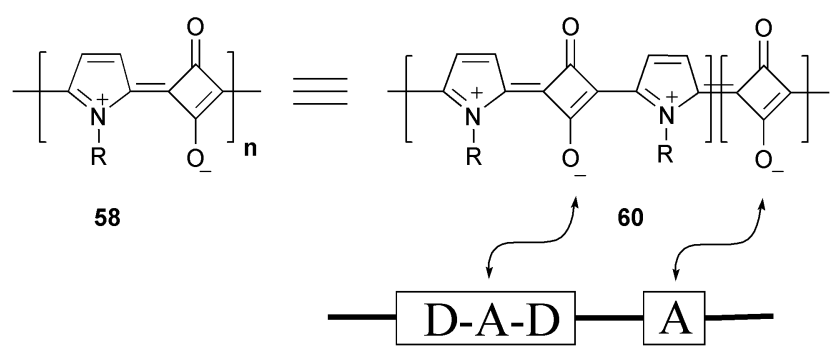

Fig. 15

the squaraine repeating unit, which is responsible for its unique optical properties is considerably reduced by the electron pull of the cyclobutene bridge. Therefore, it is reasonable to speculate that replacing of the electron deficient bridging unit with a strong electron donating group may significantly improve the optical and electronic properties of the resulting polymers.

A straightforward approach to the implementation of the above idea is difficult. For example, the direct introduction of an electron donating conjugated bridge to the squaraine dye $\mathbf{5 7}$ is not viable due to some of its inherent limitations such as solubility in solvents of preference and stability under various reagents of choice. Therefore, a rational approach to the above problem is crucial. This has been successfully illustrated by the in situ generation of squaraine dyes at specific positions of a conjugated backbone using appropriate molecular components. ${ }^{38,39}$ Bispyrroles $\mathbf{6 1 a - g}$, bridged with electron rich dialkoxydivinylbenzene moiety, are the building blocks of choice for this purpose. A-B type polycondensation of these bispyrroles with squaric acid resulted in the formation of polymers 62a-g with strong NIR absorption, which is a signature of low $E_{g}$ of these polymers (Scheme 12).

Polymers 62a-g can also be prepared through an intermediate route as shown in Scheme 13. Controlled reaction of 2 equivalents of bispyrroles with one equivalent of squaric acid forms the $\pi$-extended squaraine dyes $63 \mathbf{a}-\mathbf{g}$, which on subsequent reaction gives the polymers $62 \mathbf{a}-\mathbf{g}$.

The UV-Vis-NIR absorption spectra of $\mathbf{6 2} \mathbf{a}-\mathbf{g}$ revealed several interesting properties, which are unique to the new polymers. For example, the broad absorption of 62a-g between 600-1300 $\mathrm{nm}$ with vibronic features in comparison to the sharp absorption of 63a-g in toluene is an indication of a high degree of conjugation and planarity of the former. Presence of the electron donating moiety has significant influence on the absorption properties of $\mathbf{6 2} \mathbf{a}-\mathbf{g}$ which is evident from the comparison of the absorption spectra of 62a with that of the polysquaraine 58 (Fig. 16).

The solution and solid-state band gaps of the polymers 62a$\mathbf{g}$, which are calculated from the onset of the absorption bands, are between $0.7-1.1 \mathrm{eV}$. These values are very low when compared to other classes of conjugated polymers. The intrinsic conductivities, measured by 2-point method using rectangular pellets were in the order of $10^{-4}-10^{-7} \mathrm{~S} \mathrm{~cm}^{-1}$. In these cases, any unintentional doping of the polymers by oxygen was ruled out by comparing the UV-vis-NIR absorption spectra before and after exposure to air, which did not show any difference. The doped conductivities measured after exposing the polymers in iodine vapours were in the order of $10^{-2} \mathrm{~S} \mathrm{~cm}^{-1}$ in all cases. It is interesting to note that even though the band gaps of these polymers are very close, their intrinsic conductivities showed considerable variation. This is rationalized based on the length of the hydrocarbon side chains, which has considerable influence on the solid-state molecular packing of the polymer chains. The ordered domains present in such self-organized microstructures of $\pi$-conjugated polymers have a crucial role in their charge carrier mobility and photophysical properties.

A comparison of the X-ray diffraction patterns of a few representative polysquaraines is shown in Fig. 17. The interchain packing distance of these polymers strongly depends upon the $O$-alkyl side chains, while the interlayer $\pi$-stacking distance<smiles>[R20]c1cc(/C=C/c2cccn2[R])c([R20])cc1/C=C/c1cccn1[R]</smiles>

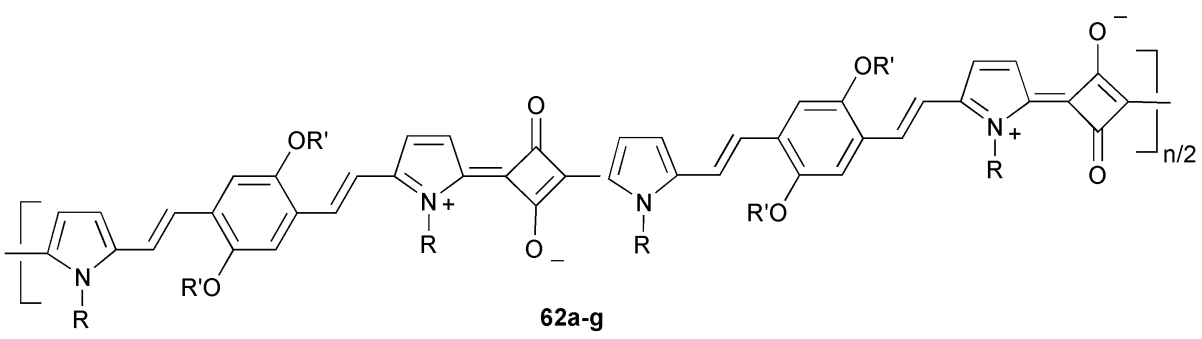

$$
\begin{array}{ll}
\text { a, } \mathrm{R}=\mathrm{CH}_{3} ; & \mathrm{R}^{\prime}=\mathrm{C}_{4} \mathrm{H}_{9} \\
\text { b, } \mathrm{R}=\mathrm{CH}_{3} ; & \mathbf{R}^{\prime}=\mathrm{C}_{8} \mathrm{H}_{17} \\
\text { c, } \mathrm{R}=\mathrm{CH}_{3} ; & \mathrm{R}^{\prime}=\mathrm{C}_{12} \mathrm{H}_{25} \\
\text { d, } \mathrm{R}=\mathrm{C}_{12} \mathrm{H}_{25} ; \mathbf{R}^{\prime}=\mathrm{CH}_{3}
\end{array}
$$



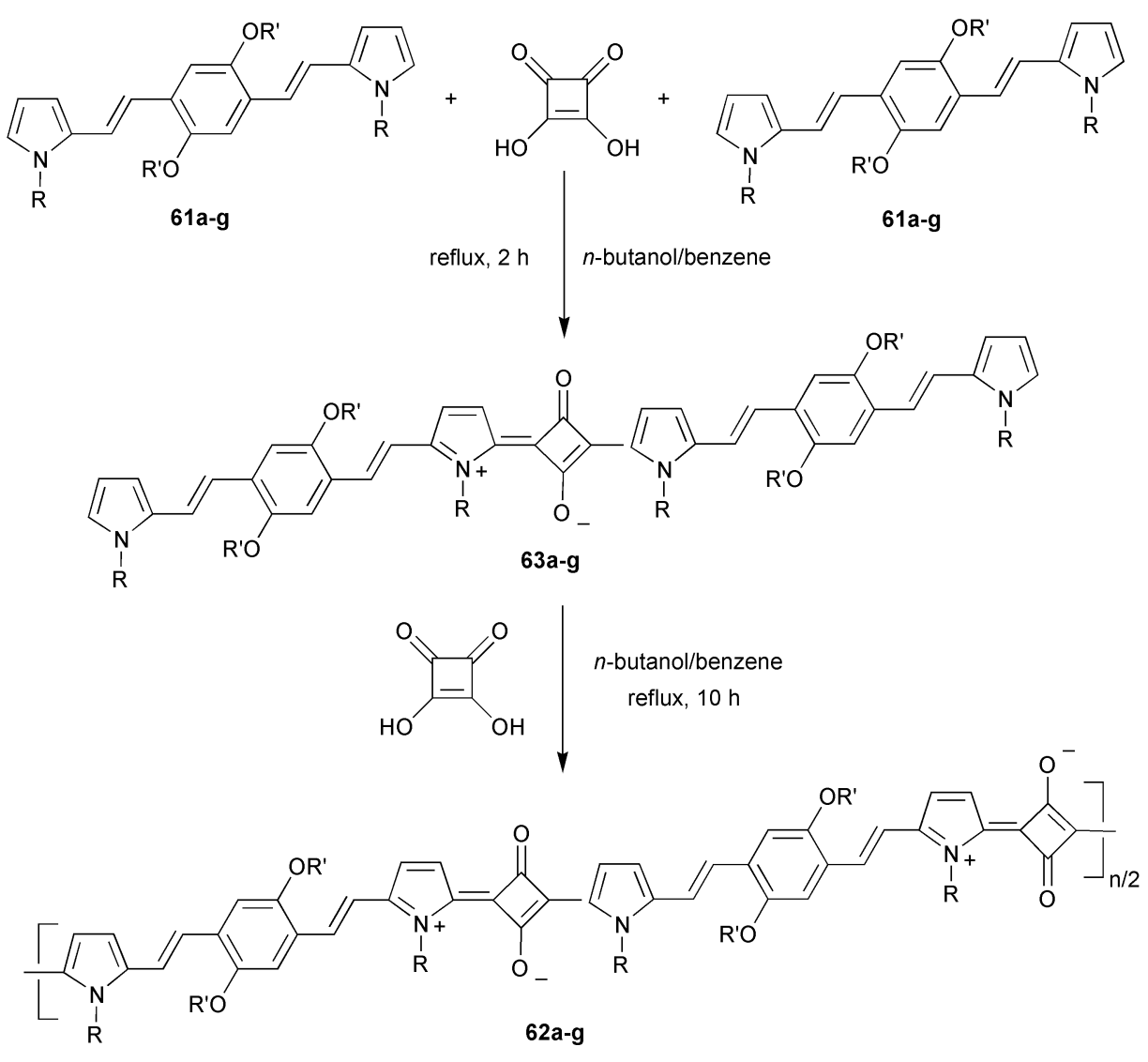

Scheme 13

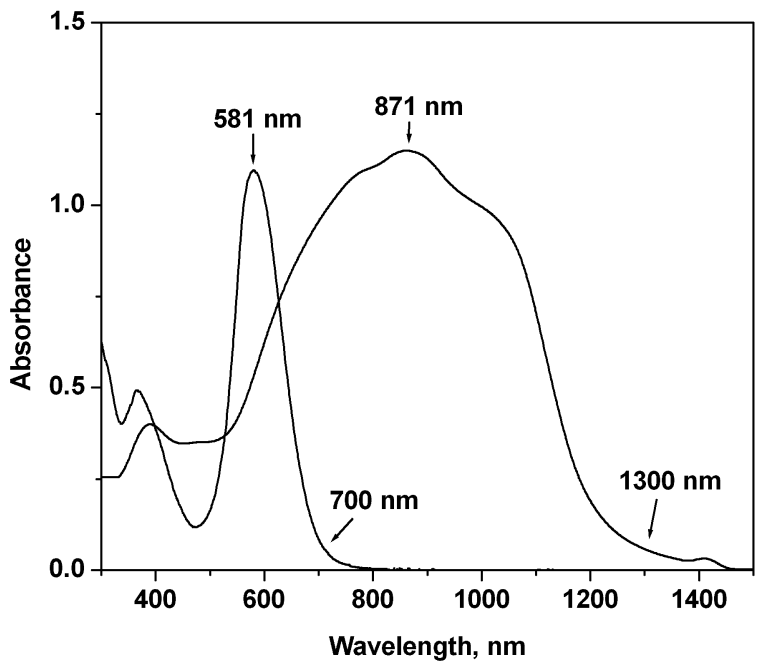

Fig. 16 Comparison of the absorption spectra of $62 \mathbf{a}$ and 58 illustrating the role of the electron donating bridging unit on electronic absorption.

at the wide-angle region remained nearly the same, independent of the variation of the side chain length. Increase of the side chain length causes considerable distortion of the stacked layers. It is interesting to note that the interchain spacing of polysquaraines is shorter than those of regioregular polyfurans and polythiophenes having identical side chains. This is the indication of the interdigitated comb like structures for polysquaraines (Fig. 18). Thus the observed variations in conductivity of $62 \mathbf{a}-\mathbf{g}$ are in good agreement with the packing distance calculated from the XRD patterns.

\section{Summary and outlook}

In order to achieve metal-like conductivity in synthetic polymers, it is important to design polymers with extremely low

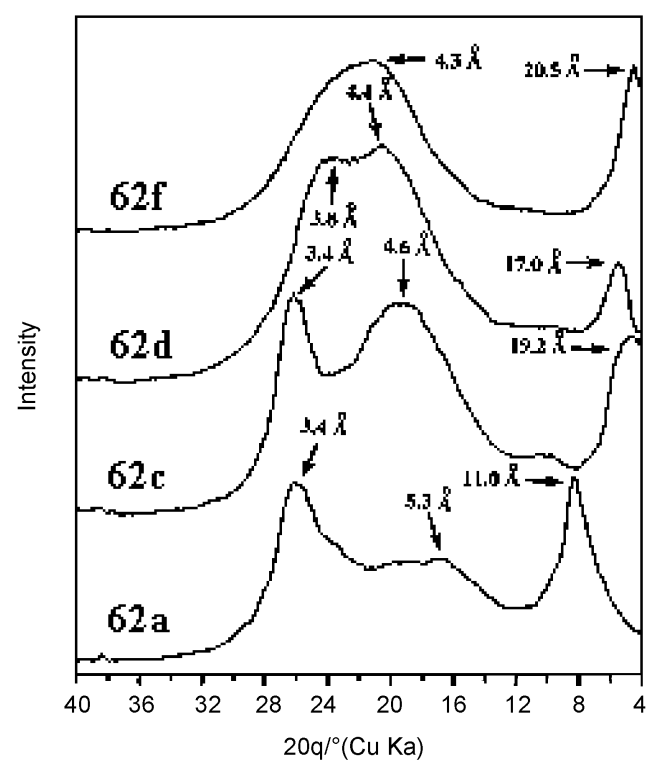

Fig. 17 XRD patterns of polysquaraines 62a, 62c, 62d and 62f (adapted from ref. 39).

band gaps. Even though donor-acceptor strategy is successful in the designing of low $E_{g}$ polymers in many cases, there are several limitations to this approach. Use of organic dyes with inherently low HOMO-LUMO gap as the building blocks is significant in this context. Squaraine dyes are the ideal candidates for this purpose as illustrated by the synthesis of a variety of low $E_{g}$ polysquaraines. Recent studies have shown that incorporation of strong electron donating conjugated bridges between donor-acceptor-donor type dyes is one of the most successful approaches in the designing of low $E_{g}$ polymers with strong NIR absorption. However, the band gaps reported in the literature for the majority of the donor-acceptor class of polymers are far from achieving metallic conductivity. There- 


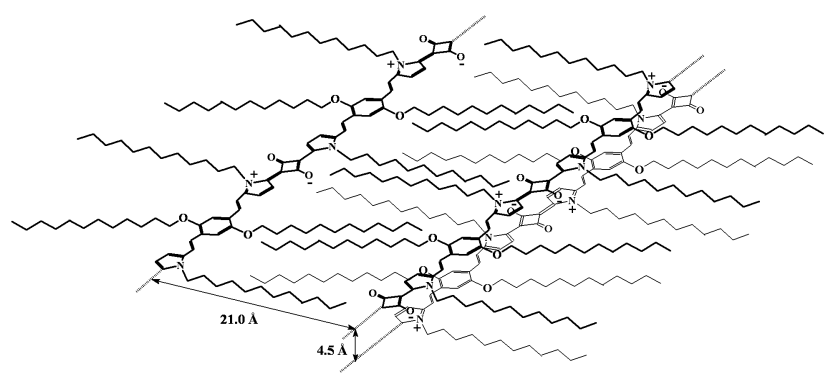

Fig. 18 Interdigitated molecular packing diagram of polysquaraine $\mathbf{6 2 g}$. The calculated $d$-spacing value for the interdigitated packing of $\mathbf{6 2 g}$ is $17.6 \AA$ whereas the observed value is $21.0 \AA$ (TITAN Version 1, MM force field, adapted from ref. 39).

fore, the topic still continues to be a challenge to chemists. A survey of the properties of polysquaraines reveals that they are potential candidates as intrinsic semiconductors, NIR absorbers and emitters, NLO materials and solar energy harvesters. Structural manipulations of squaraines and related dyes, therefore, will have tremendous potential in achieving the synthesis of polymers with extremely low band gap and strong NIR absorption.

\section{Acknowledgements}

I thank my former coworkers, Dr C. R. Chenthamarakshan and Dr J. Eldo for their contributions. Financial support by the Department of Science and Technology (DST), Government of India in the form of a Swarnajayanti Research Grant (DST/SF/ C6/99-2000) is gratefully acknowledged. This is contribution No. RRLT-PPD-164.

\section{References}

1 H. Shirakawa, E. J. Louis, A. G. MacDiarmid, C. K. Chiang and A. J. Heeger, J. Chem. Soc., Chem. Commun., 1977, 578.

2 C. K. Chiang, M. A. Druy, S. C. Gau, A. J. Heeger, E. J. Louis, A. G. MacDiarmid, Y. W. Park and H. Shirakawa, J. Am. Chem. Soc., 1978, 100, 1013.

3 J. Roncali, Chem. Rev., 1997, 97, 173and references cited therein

4 H. Meier, U. Stalmach and H. Kolshorn, Acta Polym., 1997, 48, 379.

5 S. A. Jenekhe, Nature, 1986, 322, 345.

6 H. Aota, T. Reikan, A. Matsumoto and M. Kamachi, Chem. Lett., 1998, 335.

7 U. Scherf and K. Müllen, Synthesis, 1992, 23.
8 Y. Yao, J. J. S. Lamba and J. M. Tour, J. Am. Chem. Soc., 1998, 120 2805

9 T. W. Brockmann and J. M. Tour, J. Am. Chem. Soc., 1995, 117, 4437.

10 H. A. M. van Mullekom, J. A. J. M. Vekemans and E. W. Meijer, Chem. Commun., 1996, 2163.

11 G. Brocks and A. Tol, J. Phys. Chem., 1996, 100, 1838.

12 H. A. M. van Mullekom, The Chemistry of High and Low Band Gap $\pi$ Conjugated Polymers. Ph. D. Thesis, Technishe Universiteit Eindhoven, 2000 and references cited therein.

13 H. A. Ho, H. Brisset, P. Frére and J. Roncali, J. Chem. Soc., Chem. Commun., 1995, 2309.

14 G. Zotti, S. Zecchin, G. Schiavon, A. Berlin, G. Pagani, M. Borgonovo and R. Lazzaroni, Chem. Mater., 1997, 9, 2876.

15 S.-C. Lin, J.-A. Chen, M.-H. Liu, Y. O. Su and M.-K. Leung, J. Org. Chem., 1998, 63, 5059 .

16 Q. T. Zhang and J. M. Tour, J. Am. Chem. Soc., 1998, 120, 5355.

17 C. Kitamura, S. Tanaka and Y. Yamashita, Chem. Mater., 1996, 8, 570 .

18 S. Akoudad and J. Roncali, Chem. Commun., 1998, 2081.

19 M. Karikomi, C. Kitamura, S. Tanaka and Y. Yamashita, J. Am. Chem. Soc., 1995, 117, 6791.

20 S. Tanaka and Y. Yamashita, Synth. Met., 1997, 84, 229.

21 H. A. M. van Mullekom, J. A. M. Vekemans and E. W. Meijer, Chem. Eur. J., 1998, 4, 1235.

22 A. H. Schmidt, Synthesis, 1980, 961 and references cited therein

23 K.-Y. Law, Chem. Rev., 1993, 93, 449 and references cited therein

24 A. Treibs and K. Jacob, Angew. Chem., Int. Ed. Engl., 1965, 4, 694.

25 Y.-Y. Chen and H. K. Hall, Jr., Polym. Bull., 1986, 16, 419.

26 E. E. Havinga, W. ten Hoeve and H. Wynberg, Polym. Bull., 1992, 29, 119.

27 E. E. Havinga, W. ten Hoeve and H. Wynberg, Synth. Met., 1993, 55-57, 299.

28 E. E. Havinga, A. Pomp, W. ten Hoeve and H. Wynberg, Synth. Met., 1995, 69, 581.

29 D. E. Lynch, U. Geissler, J. Kwiatowski and A. K. Whittaker, Polym. Bull., 1997, 38, 493.

30 D. E. Lynch, U. Geissler, I. R. Peterson, M. Floersheimer, R. Terbrack, L. F. Chi, H. Fuchs, N. J. Calos, B. Wood, C. H. L. Kennard and G. J. Langley, J. Chem. Soc., Perkin Trans. 2, 1997, 827.

31 D. E. Lynch, I. R. Peterson, M. Floersheimer, D. Essing, L. F. Chi, H. Fuchs, N. J. Calos, B. Wood, C. H. L. Kennard and G. J. Langley, J. Chem. Soc., Perkin Trans. 2, 1998, 779.

32 A. Ajayaghosh, C. R. Chenthamarakshan, S. Das and M. V. George, Chem. Mater., 1997, 9, 644.

33 C. R. Chenthamarakshan and A. Ajayaghosh, Chem. Mater., 1998, 10, 1657.

34 C. R. Chenthamarakshan, J. Eldo and A. Ajayaghosh, Macromolecules, 1999, 32, 251.

35 C. R. Chenthamarakshan and A. Ajayaghosh, Tetrahedron Lett., 1998, 39, 1795 .

36 C. R. Chenthamarakshan, J. Eldo and A. Ajayaghosh, Macromolecules, 1999, 32, 5846

37 D. E. Lynch, U. Geissler and K. A. Byriel, Synth. Met., 2001, 124, 385.

38 A. Ajayaghosh and J. Eldo, Org. Lett., 2001, 3, 2595.

39 J. Eldo and A. Ajayaghosh, Chem. Mater., 2002, 14, 410. 